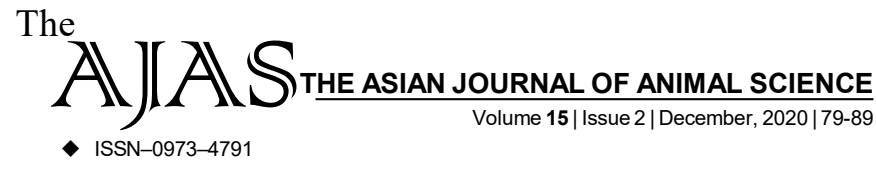

DOI : 10.15740/HAS/TAJAS/15.2/79-89 Visit us | www.researchjournal.co.in

A CASE STUDY

\title{
Animal husbandry as the driver of progress in India and Kerala
}

Biju Chacko.

Author for Corresponding -

\section{Biju Chacko}

Department of Animal Nutrition, College of Veterinary and Animal Sciences, Pookode, Wayanad (Kerala) India

Email: bijuchacko@kvasu.ac.in
ABSTRACT.......The dairy sector, which contributes to 21 per cent of the value of the agriculture and allied sectors in India, is the growth propeller of the rural economy of the country. However, extraneous factors beyond the farmer's control, for instance climatic variations such as low rainfall and heavy drought; fluctuating and many a times low prices for produce and exploitation by middlemen have cast a gloomy spell over the sector, indicating that the prospects of the agricultural sector are gloomy, as evinced by the fact that in the year 2014-15, the sector showed a negative growth $(-0.20 \%)$, from where it is struggling hard to pick up, indicating that its prospects are more or less saturated. This augurs well for the dairy sector, which grew annually at the rate of around five per cent, every year, since 2014-15 and has started asserting great and added significance, as a livelihood ensurer to the poor farmers of the country. The state of Kerala is a demographically and socially well advanced state located in the South Western region of India, having 3.34 crores of people with a population density of 859 persons per square kilometre, the third among the states in India. The present scenario, via-a-vis, both India and Kerala, with respect to feed, the costliest component, which accounts for more than 80 per cent of any animal husbandry enterprise, fodder, management practices, reproduction, disease incidence and market of dairy and meat products are discussed thread bare, by analysing the present situation, pointing out lacunas, if any and suggesting feasible, scientific and practical solutions. These recommendations for the upliftment of the sector, if implemented at the grass root level, would definitely help animal husbandry and dairying in becoming the driver of progress in India and Kerala and will speed up our onward march towards the ultimate goal of 'Aatmanirbhar Bharath'.

KEY WORDS...... Feed, Fodder, Management, Reproduction, Disease, Complete feed, Milk yield, cows

HOW TO CITE THIS ARTICLE - Chacko, Biju (2020). Animal husbandry as the driver of progress in India and Kerala. Asian J. Animal Sci., 15(1): 79-89.DOI:10.15740/HAS/TAJAS/15.2/7989.Copyright@2020:HindAgri-Horticultural Society.

ARTICLE CHRONICLE - Received : 30.07.2020; Accepted : 18.11.2020 